\title{
Tocopherols and Polyphenols in Pumpkin Seed Oil are Moderately Affected by Industrially Relevant Roasting Conditions
}

\author{
Vera Van Hoed,* Klicia A. Sampaio, Barbara Felkner, Franc Bavec, \\ Marie-Louise Scippo, François Brose, Martina Bavec, and Roland Verhé
}

Traditionally, pumpkin seed oil is obtained by pressing the seeds after a roasting pretreatment, at temperatures up to $150^{\circ} \mathrm{C}$. However, the appropriate temperatures and roasting times are under discussion. In this study, oils from seeds roasted at different temperatures $\left(60-150^{\circ} \mathrm{C}\right)$ are compared with oil from nonroasted seeds. At higher roasting temperatures, lower roasting times are required to release the oil. Both, for tocopherols and phenolic compounds, no decreasing trend with the increasing roasting temperature are observed. In contrast, the oil from non-roasted seeds have relatively low levels of tocopherols and phenolics and lacked the typical aroma. Levels of polyaromatic hydrocarbons (PAHs) are very low, ranging from not detected in oil from non-roasted seeds to $13.8 \mu \mathrm{g} \mathrm{kg}^{-1}$ in the oil from seeds roasted at $150^{\circ} \mathrm{C}$. Therefore, the choice between the studied roasting conditions may depend rather on sensory evaluations than on the content of antioxidants or of PAHs.

Practical Applications: The process of the production of virgin pumpkin oil is based on a thermal treatment of the ground seeds, favoring the separation of the lipid fraction, and giving a typical aroma of the roasted oil. Results of this research provide important information regarding the influence of roasting conditions on the quality and safety of the oil. Roasting pumpkin seeds increased the tocopherol and phenols content in the pumpkin oil, with no significant formation of PAHs. The information will be valuable and important for not only for the pumpkin oil production, but also for all the seeds submitted to a roasting treatment before extraction.

\section{Introduction}

The roasting of the pumpkin seeds is on the one hand necessary to obtain the desired color, flavor, and taste characteristics. ${ }^{[1]}$ On the other hand, it is expected that the heat treatment will adversely affect the content of poly-unsaturated fatty acids and of minor compounds. In general, among the fatty acids, the most abundant are palmitic (9.5$14.5 \%)$, stearic $(3.1-7.4 \%)$, oleic $(21.0-$ $46.9 \%)$, and linoleic $(35.6-60.8 \%){ }^{[2]}$

It has been reported that the roasting time and temperature (increase of paste temperature to $115^{\circ} \mathrm{C}$ in $50 \mathrm{~min}$ ) have important effects on the formation of volatile compounds in the seeds, which are responsible for the characteristic flavor of the oil. ${ }^{[3]}$ In another related study, the compositional changes in the pumpkin seeds were monitored during the roasting process. ${ }^{[4]}$ The content of linoleic acid decreased slightly but significantly (from 54.6 to $54.2 \%$ ), as expected due to the temperature treatment. Tocopherol content in the seeds degraded initially but increased due to a better release and extraction after breaking the cell structures. Phytosterols seemed not to be affected. Finally, the lignan secoisolaricir-

Dr. V. Van Hoed, Prof. K. A. Sampaio, B. Felkner, Prof. R. Verhé Faculty of Bioscience Engineering, Department of Organic Chemistry

Ghent University, Coupure Links 653, 9000 Ghent, Belgium

E-mail: vera_vanhoed@hotmail.com

Prof. K. A. Sampaio

Faculty of Food Engineering, Department of Food Engineering University of Campinas, Rua Monteiro Lobato 80, 13083-862,

Campinas-São Paulo, Brazil

B. Felkner

Faculty of Food Sciences

University of Warmia and Mazury, Cieszyński Square 1 (bl.43), 10-726

Olsztyn, Poland

Prof. M.-L. Scippo, F. Brose

Faculty of Veterinary Medicine, Department of Food Sciences

University of Liège, Bd de Colonster 20 (bât B 43 bis), 4000 Liège, Belgium

Prof. M. Bavec, Prof. F. Bavec

Faculty for Agriculture and Life Sciences

University of Maribor, Pivola 10, 2311 Hoce, Maribor, Slovenia

DOI: 10.1002/ejlt.201700110 esinol disappeared from the seeds during the roasting.

In the above mentioned studies, the changes were monitored in the seeds during different stages of one roasting process (till $115^{\circ} \mathrm{C}$ during $50 \mathrm{~min}$ ), and only sterols and secoisolariciresinol were analyzed in the oil which was pressed from the seeds after the total roasting time.

Choosing a higher final roasting temperature, however, will decrease the time needed to extract the oil, and on the other hand, lower roasting temperatures will increase the required heating time. From the reports concerning the phytosterols in the seeds, ${ }^{[4]}$ it is expected that the sterol content in the oils will not be much affected. However, more important differences may be expected in the content of less stable compounds such as tocopherols and phenolic alcohols and acids. It has been reported that roasting under different conditions increased the tocopherol content as well as the total phenolic compounds, leading to a higher oxidative stability. ${ }^{[5]}$ Whereas tocopherols 
were identified individually, the phenolic alcohols and acids were determined as total phenolic acids using the Folin-Ciocalteu colorimetric method. No study to date describes the influence of roasting conditions on individual phenolic acids and alcohols.

In the study concerning the effect of roasting conditions on minor components in pumpkin seed oil, ${ }^{[5]}$ pre-set combinations of temperature and time were used ( 90 vs. 110 vs. $130^{\circ} \mathrm{C}$ and 30 vs. $60 \mathrm{~min}$ roasting). The advantage is that it allows comparing different roasting times for the same temperature. However, in practice, the roasting time is adapted in order to obtain a good oil release. In general, higher temperatures require a shorter roasting time. Further, the roasting step can induce the formation of polyaromatic hydrocarbons (PAHs). PAHs belong to a group of aromatic compounds composed from aromatic rings that contain only hydrocarbon and carbon. Many PAHs have genotoxic and carcinogenic effects, and some work as synergists. ${ }^{[6-7]}$ Nevertheless, the effect of increasing roasting temperature on the PAHs formation has been exposed only recently. ${ }^{[8]}$ The authors observed that at $150^{\circ} \mathrm{C}$ light PAHs such as phenanthrene prevailed. However, at temperatures lower than $150^{\circ} \mathrm{C}$ no PAHs were detected in the samples. Increasing roasting temperature also significantly changed the composition of the volatile compounds. Among the aldehydes, 3-methylbutanal prevailed and reached the highest concentration at $150^{\circ} \mathrm{C}$. It must be remarked that in this study the roasting time was kept constant at $60 \mathrm{~min}$.

The objective of our study was to investigate the influence of roasting conditions, on the antioxidant content as well as the individual antioxidants in pumpkin seed oil, utilizing optimized temperature-time combinations for a good oil release. In addition, even though roasting temperatures did not exceed $150^{\circ} \mathrm{C}$, the levels of contaminants were determined to ensure that the levels were acceptable for human consumption.

\section{Experimental Section}

All reagents were HPLC grade or higher purity. Tocopherol standards were obtained from Calbiochem (San Diego, USA). Standards of the phenolic compounds (gallic acid [GA], caffeic acid [CA], protocatechuic acid, tyrosol, vanillic acid, vanillin, $p$-coumaric acid, o-coumaric acid, ferulic acid, sinapic acid, luteolin, and apigenin) were procured from ACROS (Geel, Belgium).

\subsection{Pumpkin Seed Oil Samples From Differently Roasted Seeds}

Oil samples were obtained from a Slovenian farm, where the oils were isolated from the seeds (variety Gleisdorfer Ölkürbis) according to following procedure. Oil processing based on the roasting process was performed in an oil-mill with a long tradition of pumpkin oil production. Cold pressing of oil was performed on an organic farm, where this kind of oil is also produced for commercial purposes. The seeds for samples were taken from one lot of seeds, which were produced mainly by integrated farmers from Prekmurje and Podravje regions (Slovenia).

For each roasting treatment, $40 \mathrm{~kg}$ milled seeds were used in a stone mill. Salt $(\mathrm{NaCl}, 200 \mathrm{~g}$ ) and water (5.31) were added. The addition of water and $\mathrm{NaCl}$ has the main goal of facilitating the release of oil from the seeds, hence increasing the oil extraction efficiency. After milling and homogenization the $40 \mathrm{~kg}$ of seeds were heated in the pan to the temperature provided by the treatments. The time of the roasting process differs according to the possibility of separation of oils from the milled seeds, which is affected by treatment temperatures (Table 1). The oils were not refined, and no chemicals, except salt $(\mathrm{NaCl})$ were added during or after the production.

All samples for this study were produced in the same farm and stored in dark bottles, under nitrogen, in the freezer until analysis. In order to avoid repeated frosting and defrosting of the samples, $50 \mathrm{ml}$ portions of each of the oils were withdrawn and stored in smaller dark bottles, at $4{ }^{\circ} \mathrm{C}$. After each opening for sampling, the nitrogen headspace was restored in the bottles.

\subsection{Tocopherol Analysis}

The tocopherols and tocotrienols were determined by normal phase HPLC following the AOCS Official Method Ce 8-89. ${ }^{[9]}$ A normal phase Alltima Silica column $(250 \times 4.6 \mathrm{~mm}$ id, ps $5 \mu \mathrm{m})$ was used. Samples were filtered through a microfilter. Tocopherols were eluted in 20 min with $n$-hexane/isopropanol $/ 99.5 / 0.5 \mathrm{v} / \mathrm{v}$ ) at a flow rate of $1.5 \mathrm{ml} \mathrm{min}^{-1}$ and a column pressure of 50 bar. For detection, a fluorescence detector Hewlett Packard 1050 Series was used with the excitation wavelength at $290 \mathrm{~nm}$ and the emission wavelength at $330 \mathrm{~nm}$.

\subsection{Solid Phase Extraction of Phenolic Compounds}

The method was based on the phenol extraction method developed for other vegetable oils, ${ }^{[10]}$ and on the methods described by Siger et al. ${ }^{[19]}$ and Andjelkovic. ${ }^{[11,20]}$ Obtained extracts were analyzed for the individual (High Performance Liquid Chromatography HPLC) and total content of phenolic compounds (Total Phenolic Compounds, TPC, Folin-Ciocalteu method).

Table 1. Roasting time and temperature of seeds for pumpkin seed oil production.

\begin{tabular}{|c|c|c|}
\hline $\begin{array}{l}\text { Treatment (roasting } \\
\text { temperature }-{ }^{\circ} \mathrm{C} \text {, combinations) }\end{array}$ & $\begin{array}{l}\text { Required time for } \\
\text { roasting (min) }\end{array}$ & No. of oil sample \\
\hline $60-70$ & 100 & PSO 11 \\
\hline 90 & 75 & PSO 6 \\
\hline 95 & 70 & PSO 1 \\
\hline 100 & 65 & PSO 12 \\
\hline 105 & 65 & PSO 2 \\
\hline 110 & 60 & PSO 10 \\
\hline 115 & 60 & PSO 9 \\
\hline 120 & 55 & PSO 3 \\
\hline 125 & 55 & PSO 8 \\
\hline 130 & 50 & PSO 4 \\
\hline 150 & 45 & PSO 7 \\
\hline 90 and 130 & 30 and 30 & PSO 5 \\
\hline 0 - cold press (CP) & & PSO 13 \\
\hline Oil mixtures: $1 / 2$ cold press and $1 / 2150$ & & PSO $14(13+7)$ \\
\hline
\end{tabular}




\subsubsection{Sample Preparation}

The oil was measured in quadruplet ( $2.5 \mathrm{~g}$ for each sample), where $0.5 \mathrm{ml}$ methanol solution of internal standard (o-coumaric acid, concentration $0.01 \mathrm{mg} \mathrm{ml}^{-1}$ ) was added to three repetitions of the oil sample. The solvent from each sample was evaporated in a rotary evaporator at $30^{\circ} \mathrm{C}$. Next, all repetitions were dissolved in $6 \mathrm{ml}$ of hexane and the turbid samples $(11,13$, and 14) were filtered over a paper filter.

The samples intended for total phenolic content analysis (Folin-Ciocalteu method) after the SPE separation were measured in triplicate without adding the internal standard.

\subsubsection{Extraction Procedure}

The samples (2.5 g of oil dissolved in $6 \mathrm{ml}$ of hexane) were applied to a diol-bonded phase column (Grace, ps $50 \mu \mathrm{m}$, pore size $60 \AA$, $500 \mathrm{mg}$ bed-size and $4 \mathrm{ml}$ column-size) at a controlled flow-rate after conditioning those columns by consecutive passing of $6 \mathrm{ml}$ of methanol and then $6 \mathrm{ml}$ of hexane. Next, the sorbent in the columns was rinsed by the consecutive passing of twice $3 \mathrm{ml}$ of hexane and then $4 \mathrm{ml}$ of hexane/ethyl acetate solution (90:10, v:v).

Finally, the phenolic compounds were eluted from the sorbent with $5 \mathrm{ml}$ of methanol. The eluents were collected in test tubes and combined in conical flasks, after which the solvent (methanol) was removed under reduced pressure in a rotary evaporator at $20^{\circ} \mathrm{C}$, with intermediate re-dissolving and mixing, until the dry phenolic compounds were concentrated on the bottom of the conical flask. The residue was re-dissolved in $0.6 \mathrm{ml}$ ( 6 times $0.1 \mathrm{ml}$ ) of methanol for LC-MS analysis and $1 \mathrm{ml}$ of methanol for the colorimetric determination.

\subsection{Phenolic Compounds Identification and Quantification by HPLC}

\subsubsection{Separation of Phenolic Compounds by HPLC}

Individual phenolic compounds were separated by reversedphase high performance liquid chromatography (HPLC) and detected by both a diode array (DAD) detector and Mass
Spectroscopy (MS) based on a chromatographic method developed for olive oil polyphenols. ${ }^{[10]}$ The Agilent 1100 LC-MSD (Agilent software v A.09.03) chromatographic system equipped with a quaternary pump, C18 column (Phenomenex-Luna $4.6 \times 250 \mathrm{~mm}, \varnothing 5 \mu \mathrm{m}, 100$ A pore size), security guard column (Phenomenex C18), vacuum degasser, autosampler, 1100 6-port autoinjector valve, and quaternary pump were used. UV-detection was performed at wavelengths of 280 and $320 \mathrm{~nm}$. The elution solvents used were A $(0.2 \%$ acetic acid in LC-MS grade water), B (methanol), and C (acetonitrile) whereby $\mathrm{B}$ and $\mathrm{C}$ solvents were mixed in a 50:50 (v/v) ratio. Flow rate was $1 \mathrm{ml} \mathrm{min}^{-1}$ and run time $72 \mathrm{~min}$. The column oven was set at $35^{\circ} \mathrm{C}$. The sample injection volume was $20 \mu l$.

\subsubsection{Identification of Phenolic Compounds by HPLC-UV-MS}

Identification of compounds was (partly) achieved by comparing their retention time, UV-absorbance spectra, and $\mathrm{m} / \mathrm{z}$ ratios to the retention times, $\mathrm{UV}$ - and $\mathrm{m} / \mathrm{z}$ ratios of the available standards. The mass spectra were recorded by Agilent G1946D (SL) quadrupole mass spectrometer (Agilent Technologies) equipped with an electrospray ionization (ESI) system and controlled by Agilent Software v. A. 09.03. Nitrogen was used as nebulizing gas at a pressure of $50 \mathrm{psi}$ and the flow was adjusted to $131 \mathrm{~min}^{-1}$. The heated capillary temperature and voltage were maintained at $350{ }^{\circ} \mathrm{C}$ and $3.5 \mathrm{kV}$, respectively. The full scan mass spectra of the phenolic compounds were measured from m/z 100 up to m/z 1000 and acquired in the negative ionization mode, at the fragmentary voltage of $70 \mathrm{eV}$.

\subsubsection{Quantification of Phenolic Compounds by HPLC-UV}

For each of the identified phenolic compounds the calibration curve $\left(\right.$ area $=$ slope $^{*}$ concentration $\left(\mu \mathrm{g} \mathrm{ml}^{-1}\right)+$ intercept) was prepared using increasing concentration of standards (protocatechuic acid, tyrosol, vanillic acid, vanillin, $p$-coumaric acid, ferulic acid, sinapic acid, luteolin, and apigenin). Molecular mass, retention time, and calibration curve properties are presented in Table 2 .

Table 2. Molecular mass, retention time, and calibration curve properties of phenolic reference compounds.

\begin{tabular}{|c|c|c|c|c|c|}
\hline Compound & Molecular weight & Retention time (min) & Calibration intercept & Curve slope & Correlation factor \\
\hline Protocatechuic acid & 154.12 & 8.38 & -0.056 & 21.56 & 0.99 \\
\hline Tyrosol & 138.17 & 9.97 & 0.006 & 12.20 & 0.99 \\
\hline Vanillic acid & 168.15 & 11.82 & -0.065 & 32.20 & 0.99 \\
\hline Vanillin & 152.15 & 13.4 & 0.038 & 91.59 & 0.99 \\
\hline$p$-coumaric acid & 164.16 & 14.49 & -0.094 & 94.03 & 0.99 \\
\hline Ferulic acid & 194.18 & 15.42 & 0.002 & 36.28 & 1.00 \\
\hline Sinapic acid & 224.21 & 15.71 & 0.024 & 13.29 & 0.99 \\
\hline Luteolin & 286.24 & 28.17 & 0.006 & 21.07 & 0.99 \\
\hline Apigenin & 270.23 & 32.5 & -0.010 & 39.86 & 1.00 \\
\hline
\end{tabular}




\subsection{Phenolic Compounds Quantification by Folin-Ciocalteu Method}

\subsubsection{Calibration Curve}

To prepare the calibration curves, a series of solutions of the standards GA and CA with increasing concentration (50;100; 150; 200; 250; $400 \mu \mathrm{g} \mathrm{ml}^{-1}$ ) was prepared. The standards were diluted with a solvent mixture methanol/water $(1: 1, \mathrm{v} / \mathrm{v})$.

\subsubsection{Sample Analysis}

One mililiter of methanol phenolic extract was added to a $100 \mathrm{ml}$ volumetric flask containing $65 \mathrm{ml}$ of deionized water. Next, $5 \mathrm{ml}$ of Folin-Ciocalteu reagent (10 times diluted) was added and mixed. After $5 \mathrm{~min}, 15 \mathrm{ml}$ of $20 \%$ sodium carbonate solution was added and then the volume in the flask was adjusted with deionized water. The solution was left for $2 \mathrm{~h}$ covered and protected from light. Each sample was prepared and analyzed in triplicate. After this time the absorbance of each solution was measured by UV-Visible Spectrophotometer Cary 50 at $760 \mathrm{~nm}$ against the blank (water).

\subsubsection{Quantification of Phenolic Compounds by Folin- Ciocalteu}

Quantification of the total content of phenolic compounds was based on the calibration curves. The relation between the standards concentration and the absorbance was plotted resulting in linear equations with $y=$ area and $x=$ concentration $\left(\mu \mathrm{g} \mathrm{ml}^{-1}\right)\left(\mathrm{GA}: Y=0.001 \mathrm{x}-0.0140\left(R^{2}=0.9996\right)\right.$; $\mathrm{CA}: \mathrm{Y}=0.011$ $\mathrm{X}+0.0055\left(R^{2}=0.9994\right)$.

\subsection{Determination of PAHs in Pumpkin Seed Oils}

The levels of PAHs in the pumpkin seed oil samples were determined in a specialized laboratory (Faculté de Medicine Veterinaire, Dpt. Sciences denrées alimentaires, Université de Liège, Belgium). One gram of oil was extracted and purified, ${ }^{[12]}$ and analyzed using HPLC-FLD according to published methods. ${ }^{[13-14]}$

\subsection{Statistical Evaluation}

Statistical analysis was performed using SAS version 9.2 for Windows. Statistical differences between the oil samples were estimated by applying one-way ANOVA and using the Duncan's test at a significance level of $5 \%(p<0.05)$. All analyses were carried out in triplicate. Standard deviations were calculated using Microsoft Excel 2007 software. The One-Way Anova is used to evaluate if the means are significantly different from one another or if they are relatively the same.

\section{Results and Discussion}

\subsection{Influence of Processing on Tocopherols Content}

\subsubsection{Total Tocopherol Content}

The tocopherol composition of the oils obtained from differently processed seeds is represented in Table 3. By comparing the data in Table 3 it can be seen that there are significant differences $(p<0.05)$ between the cold pressed oil and the oils obtained from the roasted seeds, both in respect to the content and composition of tocopherols. The total tocopherol content varied between 584 and $687 \mathrm{mg} \mathrm{kg}^{-1}$ (samples 12 and 1 , respectively), which are intermediate values compared to those reported for Styrian

Table 3. Tocopherol content of pumpkin seed oils after with different seed roasting conditions. Values are means of three repetitions.

\begin{tabular}{|c|c|c|c|c|c|c|c|}
\hline \multirow[b]{2}{*}{ Sample } & \multicolumn{2}{|c|}{ Roasting } & \multicolumn{2}{|c|}{ a-tocopherol } & \multicolumn{2}{|c|}{$\gamma$-tocopherol } & \multirow{2}{*}{$\frac{a-T+\gamma-T}{m g ~ k g}$} \\
\hline & $\mathrm{T}\left({ }^{\circ} \mathrm{C}\right)$ or combination & Time $(\min )$ & $\mathrm{mg} \mathrm{kg}^{-1}$ & $\%$ & $\mathrm{mg} \mathrm{kg}^{-1}$ & $\%$ & \\
\hline PSO 11 & $60-70$ & 100 & $45.8 \pm 2.3 \mathrm{bdc}$ & 7.3 & $580.4 \pm 10.4$ fbecd & 92.7 & $626.2 \pm 12.7 \mathrm{bcd}$ \\
\hline PSO 6 & 90 & 75 & $37.7 \pm 0.9 \mathrm{de}$ & 6.3 & $558.4 \pm 3.2 \mathrm{fed}$ & 93.7 & $596.2 \pm 4.1 \mathrm{~cd}$ \\
\hline PSO 1 & 95 & 70 & $55.4 \pm 8.7 a$ & 8.1 & $631.6 \pm 34.2 a$ & 91.9 & $687.0 \pm 42.9 a$ \\
\hline PSO 12 & 100 & 65 & $32.6 \pm 6.2 \mathrm{fe}$ & 5.6 & $551.9 \pm 27.6 \mathrm{fe}$ & 94.4 & $584.5 \pm 33.8 \mathrm{~d}$ \\
\hline PSO 2 & 105 & 65 & $48.1 \pm 8.6 \mathrm{bac}$ & 7.8 & $571.3 \pm 33.2 \mathrm{fbecd}$ & 92.2 & $619.4 \pm 41.8 \mathrm{bcd}$ \\
\hline PSO 10 & 110 & 60 & $27.8 \pm 1.7 f$ & 4.5 & $588.4 \pm 0.9 b c d$ & 95.5 & $616.2 \pm 2.6 \mathrm{bcd}$ \\
\hline PSO 9 & 115 & 60 & $51.5 \pm 6.4 \mathrm{ba}$ & 7.9 & $603.9 \pm 7.4 \mathrm{ba}$ & 92.1 & $655.4 \pm 13.8 \mathrm{ba}$ \\
\hline PSO 3 & 120 & 55 & $46.4 \pm 0.7 \mathrm{bdac}$ & 7.4 & $582.9 \pm 8.3 \mathrm{becd}$ & 92.6 & $629.2 \pm 9.0 b c$ \\
\hline PSO 8 & 125 & 55 & $37.2 \pm 2.7 \mathrm{de}$ & 6.4 & $547.2 \pm 20.0 f$ & 93.6 & $584.4 \pm 22.7 d$ \\
\hline PSO 4 & 130 & 50 & $41.9 \pm 7.8 \mathrm{dec}$ & 6.7 & $582.2 \pm 7.7 \mathrm{becd}$ & 93.3 & $624.2 \pm 15.5 b c d$ \\
\hline PSO 7 & 150 & 45 & $39.6 \pm 0.9 \mathrm{dec}$ & 6.6 & $560.7 \pm 2.0$ fed & 93.4 & $600.3 \pm 2.9 \mathrm{~cd}$ \\
\hline PSO 5 & $90+130$ & 60 & $37.9 \pm 1.0 \mathrm{de}$ & 6.3 & $567.2 \pm 15.8 \mathrm{fecd}$ & 93.7 & $605.1 \pm 16.8 \mathrm{~cd}$ \\
\hline PSO 13 & $\mathrm{CP}$ & & $32.9 \pm 4.5 \mathrm{fe}$ & 5.6 & $553.5 \pm 14.7 \mathrm{fed}$ & 94.4 & $586.4 \pm 19.2 \mathrm{~cd}$ \\
\hline PSO $14(13+7)$ & $C P+150$ & 45 & $52.4 \pm 5.5 \mathrm{ba}$ & 8.1 & $597.5 \pm 18.6 b c$ & 91.9 & $649.9 \pm 24.1 \mathrm{ba}$ \\
\hline
\end{tabular}

Different letters within columns indicate significant differences $(p<0.05)$ among the samples. 
pumpkin seed oils ${ }^{[15]}$ (up to $282 \mathrm{mg} \mathrm{kg}^{-1} \alpha$-tocopherol and $800 \mathrm{mg} / \mathrm{kg} \gamma$-tocopherol) and higher than reported for Serbian cultivars [5] $\left(269.79-350.98 \mathrm{mg} \mathrm{kg}^{-1}\right.$ total tocopherols). It is known that tocopherol content in vegetable oils is dependent on variety, geographical origin, and processing conditions. ${ }^{[16]}$

\subsubsection{Tocopherol Composition}

In all samples $\gamma$-tocopherol (547-632 $\mathrm{mg} \mathrm{kg}^{-1}$ ) was most abundant (approx. 92-95\%). In normal phase HPLC, the $\beta$ and $\gamma$-tocopherol peaks are well separated, if both are present. However, $\beta$-tocopherol was detected in none of the samples, as confirmed by comparing with a 4-tocopherol standard mix. ${ }^{[17]}$ The peak of $\alpha$-tocopherol co-eluted in many cases with an unknown compound, which could not be quantified separately (approximate concentration $5-8 \%$ of the peak). The shoulder peak could be attributed to the presence of $\alpha$ tocomonoenol, which was previously identified in crude palm oil samples. ${ }^{[18]}$ In the Table 2, the quantification is done for the total peak, with shoulder $\left(27-55 \mathrm{mg} \mathrm{kg}^{-1}\right)$. Finally, $\delta$ tocopherol was detected as well but only in trace amounts. This pumpkin seed oil was obtained from the variety Gleisdorfer Ölkürbis in Slovenia. In the oil from the Olinka pumpkin seed variety (Serbia), lower values were reported of $(\beta+\gamma)$-tocopherol (197-267 $\left.\mathrm{mg} \mathrm{kg}^{-1}\right)$, together with 48-77 mg $\mathrm{kg}^{-1} \alpha$-tocopherol and minor but quantifiable amounts of $\delta$ tocopherol $\left(18-21 \mathrm{mg} \mathrm{kg}^{-1}\right) \cdot{ }^{[5]}$

\subsubsection{Influence of Roasting Conditions on $\gamma$-Tocopherol Content}

The quantification of $\gamma$-tocopherol was most reliable because of its lower relative standard deviation and because it did not suffer from co-elution. Therefore, the influence of processing is interpreted only for this tocopherol. By comparing all the treatments, mathematically significant differences $(p<0.05)$ can be seen in the content of $\gamma$-tocopherol. It has been reported that during a roasting process the tocopherols content first decreases but afterwards increases again, probably due to breaking the cell structures. ${ }^{[4]}$ In the present study, focusing on the industrially relevant conditions, necessary time for the release of oil was decreased with increasing roasting temperature, which is most probably the reason for the similar effects of all treatments on the tocopherol content. Further, other components which were not assessed, may have varied between the treatments, such as phospholipids, carotenoids, or oxidation products, which can have an influence on the oxidative stability of the oil, and cause small variation in the final content of tocopherols.

\subsubsection{Extraction Method for Phenolic Compounds From Pumpkin Seed Oil}

The extraction protocol was based on the phenol extraction method developed for other vegetable oils, ${ }^{[10]}$ and on the method described by Siger et al. ${ }^{[19]}$ and Andjelkovic. ${ }^{[20]}$ This original SPE method did not give satisfactory results with pumpkin seed oil, yielding turbid final solutions of phenolic compounds, a low yield, and poor detection of phenolic compounds during the HPLC analysis of the extract. By adapting the conditions for solid phase extraction to the pumpkin seed oil matrix it was possible to obtain clear samples and, at the same time, to avoid losses of phenols, and obtain a good detection in HPLC.

\subsection{Identification of Phenolic Compounds in Pumpkin Seed Oil by HPLC-MS}

Reversed-phase high performance liquid chromatography (with UV and MS) was used for the separation and quantification of individual phenolic compounds. The identification was done on the basis of retention times, molecular masses, and UV-spectra (Table 3). Eight peaks could be identified based on the UV absorbance, retention time, and mass spectrum obtained with the LC-MS system (Table 4).

Regarding their molecular masses, two peaks at 57.47 and $60.42 \mathrm{~min}$ were most probably flavonols, but their exact structure could not be defined and they were therefore not included in the quantification based on HPLC results. Unidentified peaks were not taken under consideration in the following quantification based on HPLC results.

However, in this study the major goal was not the full profiling but to assess the influence of the roasting conditions on the overall antioxidants content (tocopherols, phenolic compounds). Total phenolic contents from HPLC quantification will be compared with the TPC from the spectrophotometric method.

\subsection{Quantification of Phenolic Compounds in Pumpkin Seed Oil by HPLC}

In Table 5, the individual and total phenolic contents of the pumpkin seed oils are presented. Phenolic profiles were collected by HPLC at 280 and $320 \mathrm{~nm}$. Identification was done by combining recording UV and mass spectra with standard compounds and literature data. All samples of pumpkin seed oil contained tyrosol, $p$-coumaric acid, and ferulic acid. Most of the samples contained vanillic acid whereas vanillin was present in three samples. Apigenin was identified in four samples and protocatechuic acid in only two samples, at high concentration but with very high standard deviation. The treatment of PSO 2

Table 4. Phenolic compounds in pumpkin seed oils (PSO 3 sample).

\begin{tabular}{lllc}
\hline Retention time $(\mathrm{min})$ & UV max & MS $\left(\mathrm{M}^{-}\right)$ & Identification \\
\hline 8.38 & 287 & 153 & Protocatechuic acid \\
9.93 & 290 & 137 & Tyrosol \\
11.67 & 278 & 167 & Vanillic acid \\
13.39 & 278 & 151 & Vanillin \\
14.47 & 310 & 163 & $p$-coumaric acid \\
15.41 & 325 & 193 & Ferulic acid \\
32.07 & 287 & 269 & Apigenin \\
\hline
\end{tabular}


Table 5. Identified and quantified phenolic compounds in pumpkin seed oils ( $\mu \mathrm{g}$ of phenol $\mathrm{g}^{-1}$ oil). Values are means of three repetitions.

\begin{tabular}{|c|c|c|c|c|c|c|c|c|c|c|}
\hline & $\begin{array}{l}\text { Roasting } \\
\mathrm{T}\left({ }^{\circ} \mathrm{C}\right)\end{array}$ & $\begin{array}{l}\text { Roasting } \\
\text { time (min) }\end{array}$ & $\begin{array}{c}\text { Proto-catechuic } \\
\text { acid }\end{array}$ & Tyrosol & $\begin{array}{l}\text { Vanillic } \\
\text { acid }\end{array}$ & Vanillin & $\begin{array}{c}p \text {-coumaric } \\
\text { acid }\end{array}$ & $\begin{array}{l}\text { Ferulic } \\
\text { acid }\end{array}$ & Apigenin & Total \\
\hline PSO 11 & $60-70$ & 100 & & $2.4 \pm 0.5 d$ & $0.9 \pm 0.1 \mathrm{cb}$ & & $0.1 \pm 0.0 f$ & $0.3 \pm 0.0 \mathrm{dc}$ & & $3.7 \pm 0.5 \mathrm{dfe}$ \\
\hline PSO 6 & 90 & 75 & & $2.3 \pm 0.4 \mathrm{~cd}$ & & $0.1 \pm 0.0 \mathrm{a}$ & $0.2 \pm 0.0 \mathrm{de}$ & $0.5 \pm 0.1 c$ & & $3.2 \pm 0.4 \mathrm{fe}$ \\
\hline PSO 1 & 95 & 70 & & $0.6 \pm 0.3 \mathrm{e}$ & & & $0.2 \pm 0.0 \mathrm{fe}$ & $0.1 \pm 0.0 \mathrm{e}$ & & $0.8 \pm 0.3 \mathrm{~g}$ \\
\hline PSO 12 & 100 & 65 & & $2.3 \pm 0.7 d$ & $0.1 \pm 0.0 \mathrm{~d}$ & & $0.2 \pm 0.0 \mathrm{fe}$ & $0.1 \pm 0.0 f$ & & $2.7 \pm 0.7 f$ \\
\hline PSO 2 & 105 & 65 & $6.0 \pm 2.6 a$ & $3.9 \pm 1.4 b$ & $0.8 \pm 0.6 \mathrm{cb}$ & & $0.5 \pm 0.0 \mathrm{ba}$ & $0.4 \pm 0.2 c$ & $0.2 \pm 0.0 \mathrm{a}$ & $11.8 \pm 3.0 \mathrm{a}$ \\
\hline PSO 10 & 110 & 60 & & $3.7 \pm 0.1 \mathrm{cb}$ & $0.7 \pm 0.2 \mathrm{cb}$ & & $0.2 \pm 0.0 \mathrm{de}$ & $0.1 \pm 0.0 \mathrm{e}$ & & $4.8 \pm 0.3 \mathrm{dc}$ \\
\hline PSO 9 & 115 & 60 & & $3.7 \pm 0.5 \mathrm{cb}$ & $2.2 \pm 0.0 \mathrm{a}$ & & $0.3 \pm 0.0 \mathrm{dc}$ & $0.2 \pm 0.0 \mathrm{de}$ & & $6.3 \pm 0.5 b c$ \\
\hline PSO 3 & 120 & 55 & $6.2 \pm 3.6 \mathrm{a}$ & $4.7 \pm 1.3 b$ & $0.5 \pm 0.2 \mathrm{cb}$ & $0.5 \pm 0.3 a$ & $0.4 \pm 0.0 \mathrm{bc}$ & $0.4 \pm 0.2 c$ & $0.2 \pm 0.1 \mathrm{a}$ & $12.9 \pm 3.9 \mathrm{a}$ \\
\hline PSO 8 & 125 & 55 & & $4.7 \pm 1.1 b$ & & & $0.3 \pm 0.0 \mathrm{dc}$ & $0.3 \pm 0.0 \mathrm{dc}$ & & $5.3 \pm 1.1 \mathrm{dc}$ \\
\hline PSO 4 & 130 & 50 & & $6.3 \pm 0.8 \mathrm{a}$ & $1.1 \pm 0.5 b$ & & $0.5 \pm 0.1 \mathrm{a}$ & $1.8 \pm 0.2 \mathrm{a}$ & $0.2 \pm 0.0 \mathrm{a}$ & $10.0 \pm 1.0 \mathrm{ba}$ \\
\hline PSO 7 & 150 & 45 & & $7.3 \pm 0.7 a$ & $0.5 \pm 0.0 c$ & & $0.6 \pm 0.1 \mathrm{a}$ & $0.9 \pm 0.1 b$ & $0.2 \pm 0.0 \mathrm{a}$ & $9.4 \pm 0.7 \mathrm{ba}$ \\
\hline PSO 5 & $90+130$ & 60 & & $3.4 \pm 0.2 \mathrm{cbd}$ & & $0.3 \pm 0.2 \mathrm{a}$ & $0.4 \pm 0.1 \mathrm{dc}$ & $0.5 \pm 0.0 c$ & & $4.6 \pm 0.6 \mathrm{dce}$ \\
\hline
\end{tabular}

Different letters within columns indicate significant differences $(p<0.05)$ among the samples.

and 3 did not differ so much from the others to explain the unique presence of protocatechuic acid or absence of the interference. It seems more probable that the selected extraction method has a good repeatability for most identified phenolic compounds but not for protocatechuic acid (and possible interference). Moreover, for those two samples PSO 2 and 3, high standard deviations were observed as well for the other phenolic compounds. All bottles were placed $14 \mathrm{~h}$ in advance at room temperature in the dark and thoroughly shaken before sampling, but the variability in those samples was still higher.

No phenols were detected in cold-pressed pumpkin seed oil (PSO 13), neither in the mixture of this oil with PSO 7 (= PSO 14). It is unlikely that the cold pressed sample did not contain any polyphenols but the failure to detect them can be caused by the necessity to filter the hexane solution of the heavily turbid oils before the application on the SPE columns and HPLC analysis.

PSO 5 , heated during $30 \mathrm{~min}$ at $90^{\circ} \mathrm{C}$ and $30 \mathrm{~min}$ at $130^{\circ} \mathrm{C}$, has an intermediate content of tyrosol, $p$-coumaric acid, and ferulic acid, compared to samples 6 and 4, which have been treated at 90 and $130^{\circ} \mathrm{C}$, respectively. However, for the other phenolic compounds, this relationship was not confirmed. The samples were obtained by roasting at $90^{\circ} \mathrm{C}(30 \mathrm{~min})$ followed by $130^{\circ} \mathrm{C}(30 \mathrm{~min})$ due to two main reasons: (1) the two roasting temperatures are generally used in the industrial reality, in order to facilitate oil release and improve taste and (2) the mixture of roasted and cold pressed oil allows an intermediate taste profile.

At first sight surprisingly, no decreasing trend can be observed with increasing roasting temperature. Taking into account all identified phenolic compounds; the highest total phenol content quantified by HPLC was found for sample PSO 3 , heated at $120^{\circ} \mathrm{C}$, and sample PSO 2, heated at $105^{\circ} \mathrm{C}$. Based on the sum all compounds except protocatechuic acid, the highest phenolic content was seen for the sample heated at $130{ }^{\circ} \mathrm{C}$ during $50 \mathrm{~min}$
(PSO 4), followed by the samples heated at $150{ }^{\circ} \mathrm{C}$ (PSO 7), $120^{\circ} \mathrm{C}$ (PSO 3), $115^{\circ} \mathrm{C}$ (PSO 9), and $105^{\circ} \mathrm{C}$ (PSO 2). In addition, for the samples with different roasting temperature but the same roasting time, the levels of phenolic compounds seemed to increase with roasting temperature, which is observed by comparing sample PSO 12 with PSO 2, and PSO 10 with PSO 9. This could be linked to a better extraction of the polyphenols at higher temperatures. However, this evaluation is not valid for PSO 3 compared to PSO 8. Thus, it was not possible to correlate all differences in polyphenol profile to the roasting temperature/ time combinations. Therefore, other factors must have caused part of the differences. It is known that the polyphenols are hydrophilic compounds, possibly they did undergo an incomplete transfer from the seeds during the different processes. Further, other components may have influenced the final polyphenol content as in the case of tocopherols.

Overall, there is much more variation in the identified and quantified phenolic compounds than in the tocopherols content. While a clear trend cannot be seen, it seems that the higher temperature combined with shorter roasting time (samples PSO $4,7)$ favors the extraction of tyrosol, $p$-coumaric acid, and ferulic acid, three compounds which were clearly more abundant in PSO 4 and 7 than in the other samples.

\subsection{Quantification of Total Phenolic Content by Folin- Ciocalteu Method}

The spectrophotometric method using the Folin-Ciocalteu reagent is widely used for the determination of the total phenol content. ${ }^{[10]}$ The phenols were isolated by solid phase extraction as described above.

Total phenolic concentrations (TPC) measured in 14 pumpkin seed oil samples ranged from 72.8 to $326.6 \mu \mathrm{g}$ of 
GA equivalents and from 70.5 to $301.2 \mu \mathrm{g}$ of CA equivalents per $\mathrm{g}$ of oil (Table 6).

Sample PSO 10 had the highest TPC value, whereas the lowest level of phenolic compounds by spectrometry was found in sample PSO 13, the cold pressed pumpkin seed oil. In contrast to the HPLC method, where no peaks were detected at all for the cold pressed oil, the Folin-Ciocalteu method permitted to calculate a concentration of phenolic compounds, although for both methods the cold pressed samples had been filtrated before SPE analysis. Either the filtration selectively removed all (phenolic and possibly other) compounds detected in HPLC, and/or, more probably, the result is overestimated in the FolinCiocalteu method.

No correlation between extraction temperature and TPC could be observed. Furthermore, the sum of quantified phenolic compounds as determined by HPLC did not correlate with the colorimetrically determined total phenol content. This was not unexpected, because in HPLC only the identified simple phenolic compounds were quantified, which is an underestimation, not calculating possible phenols bound to sugars while the colorimetric method can suffer of overestimation as it measures all compounds which absorb at the wavelength of determination. The quantification via FolinCiocalteu was higher compared to the HPLC results. Total Phenolic Compounds were compared with the levels found by other researchers. In literature, widely different values are reported for the spectrophotometric determined TPC of pumpkin seed oil: $25-51 \mathrm{mg} \mathrm{GAE} \mathrm{kg}^{-1}$ for pumpkin seed oil from different origins ${ }^{[11,19]}$; and up to $20 \mathrm{mg} \mathrm{kg}^{-1}$ in roasted versus only $4 \mathrm{mg} \mathrm{kg}^{-1}$ in cold pressed pumpkin seed oil. ${ }^{[5]} \mathrm{On}$ the other hand, Total Phenolic Compounds quantified by another research team ${ }^{[21]}$ were considerably higher $(980 \mu \mathrm{g}$ $\mathrm{GAE} \mathrm{g}^{-1}$ ) than in the current study. Natural variations in phenolic contents occur without doubt, but an important problem in comparing these results, may be the different methodologies used by the authors for the phenol extraction and analytical method, due to the lack of a standardized method.

\subsection{Influence of Processing on the Content of Contaminants (PAHs)}

From the results presented above, an increasing roasting temperature of the pumpkin seeds did not have detrimental effects on the antioxidant contents in the oil. However, it is known that the roasting process can induce the presence of contaminants such as PAHs in the oil. The roasting process may give rise to levels of PAHs above the acceptable limits, as has been reported before. ${ }^{[15]}$ In a set of Styrian (Austrian) pumpkin seed oils that were roasted under unfavorable conditions (too high temperature), PAH concentrations of up to $120 \mathrm{ug} \mathrm{kg}^{-1}$ were reported for the light fraction, and up to $3 \mathrm{\mu g} \mathrm{kg}^{-1}$ for the heavy-fraction PAHs. Optimization of the roasting conditions has led to a decrease of the heavy-fraction PAH to under the limits of detection and a decrease of the remaining light-fraction PAHs to below $40 \mu \mathrm{gg}^{-1}$, which is a level frequently found in edible oil. ${ }^{[15]}$

However, the European Commission has set lower limits. ${ }^{[22]}$ A limit of $2 \mu \mathrm{g} \mathrm{kg}^{-1}$ applies for benzo(a)pyrene in oils and fats for direct human consumption. Further, a maximum limit was set to $10 \mu \mathrm{g} \mathrm{kg}^{-1}$ for the sum of four marker compounds, being benzo(a)pyrene, benzo(a)anthracene, benzo(b)fluoranthene, and chrysene. Therefore, roasting conditions should not only be based on sensory properties and differences in composition, but the levels of PAHs in the oil should be monitored as well.

Table 6. Total phenolic content (TPC) in pumpkin seed oils, as $\mu \mathrm{g}$ gallic acid equivalents (gae) $\mathrm{g}^{-1}$ oil and $\mu \mathrm{g}$ caffeic acid equivalents $\mathrm{g}^{-1}$ oil. Values are means of three repetitions.

\begin{tabular}{|c|c|c|c|c|}
\hline & $\begin{array}{l}\text { Roasting } \\
\mathrm{T}\left({ }^{\circ} \mathrm{C}\right)\end{array}$ & $\begin{array}{l}\text { Roasting } \\
\text { time (min) }\end{array}$ & $\operatorname{CAE}\left(\mu \mathrm{g} \mathrm{g}^{-1}\right)$ & $\mathrm{CAE}\left(\mu \mathrm{g} \mathrm{g}^{-1}\right)$ \\
\hline PSO 11 & $60-70$ & 100 & $83.2 \pm 4.3 \mathrm{dfe}$ & $77.2 \pm 3.9 \mathrm{dfe}$ \\
\hline PSO 6 & 90 & 75 & $156.3 \pm 8.7 b$ & $143.6 \pm 7.9 b$ \\
\hline PSO 1 & 95 & 70 & $89.1 \pm 2.2 \mathrm{dc}$ & $82.5 \pm 2.0 d c$ \\
\hline PSO 12 & 100 & 65 & $80.9 \pm 4.2 \mathrm{gfe}$ & $75.0 \pm 3.8 \mathrm{gfe}$ \\
\hline PSO 2 & 105 & 65 & $76.3 \pm 2.9 \mathrm{hg}$ & $70.9 \pm 2.6 \mathrm{hg}$ \\
\hline PSO 10 & 110 & 60 & $326.6 \pm 7.8 a$ & $298.4 \pm 7.1 \mathrm{a}$ \\
\hline PSO 9 & 115 & 60 & $272.9 \pm 10.3 \mathrm{ba}$ & $249.6 \pm 9.4 \mathrm{ba}$ \\
\hline PSO 3 & 120 & 55 & $84.7 \pm 5.3 \mathrm{dfe}$ & $78.5 \pm 4.8 \mathrm{dfe}$ \\
\hline PSO 8 & 125 & 55 & $130.5 \pm 17.8 b c$ & $120.1 \pm 16.1 \mathrm{bc}$ \\
\hline PSO 4 & 130 & 50 & $79.4 \pm 3.1 \mathrm{hgf}$ & $73.7 \pm 2.8 \mathrm{hgf}$ \\
\hline PSO 7 & 150 & 45 & $136.3 \pm 5.9 b c$ & $125.4 \pm 5.3 \mathrm{bc}$ \\
\hline PSO 5 & $90+130$ & 60 & $88.6 \pm 2.4 \mathrm{dce}$ & $82.1 \pm 2.2 \mathrm{dce}$ \\
\hline PSO 13 & $\mathrm{CP}$ & - & $72.8 \pm 8.9 h$ & $67.7 \pm 8.1 \mathrm{~h}$ \\
\hline PSO 14 & $C P+150$ & & $81.3 \pm 4.5 \mathrm{dgfe}$ & $75.4 \pm 4.1 \mathrm{dgfe}$ \\
\hline
\end{tabular}

Different letters within columns indicate significant differences $(p<0.05)$ among the samples. CP $=$ cold pressed (cfr Table 1$)$. 
The samples from Slovenia, used in the current study, were produced under varying roasting conditions, and therefore the levels of PAHs were important quality parameters. Samples were analyzed in a specialized laboratory for the analysis of PAHs levels (Faculté de Medicine Veterinaire, Dpt. Sciences denrées alimentaires, Université de Liège, Belgium). In all samples, the total PAH content was far below the $40 \mu \mathrm{g} \mathrm{kg}^{-1}$ found by other researchers, ranging from not detectable/not quantifiable for all tested compounds in the nonroasted sample PSO 13 , to $13.8 \mu \mathrm{g} \mathrm{kg}^{-1}$ for the sample roasted at $150^{\circ} \mathrm{C}$, nr. PSO 7. This PSO 7 was the only sample where benzo(a)pyrene was detected, to a level of $1 \mu \mathrm{g} \mathrm{kg}^{-1}$, below the limit of $2 \mu \mathrm{g} \mathrm{kg}^{-1}$ set by the European Commission. Further, the sum of the four marker compounds was always below $10 \mathrm{\mu g} \mathrm{kg}^{-1}$, with a max of $8,1 \mathrm{\mu g} \mathrm{kg}^{-1}$ for the PSO 7 sample roasted at $150{ }^{\circ} \mathrm{C}$. However, as was the case for the tocopherols and phenolic compounds, a real correlation of PAH concentration with roasting temperature could not be observed, probably linked with the decreasing roasting time for the range of temperatures studied (90$\left.150^{\circ} \mathrm{C}\right)$. Overall, all samples contained very low levels of PAHs, which can be attributed to the continuous search for optimized roasting conditions. These findings are confirmed by Potocnik and Kosir, ${ }^{[8]}$ who observed that up to $150^{\circ} \mathrm{C}$ no PAHs were detected in the samples, and only after roasting the pumpkin seeds for $1 \mathrm{~h}$ at $150^{\circ} \mathrm{C}$ some formation occurred, all at very low concentrations.

\subsection{Conclusions}

From the analyses conducted in this study, it appeared that the tocopherol content varied very little between the different temperature-time combinations, while larger variations were observed for the phenolic content. However, the expected decrease with higher temperatures was not seen. The less specific Folin-Ciocalteu method showed large and apparently uncorrelated variations in TPC, while the specific HPLC analysis suggested that certain individual phenolic compounds were present in higher levels after a shorter treatment at higher temperatures. Further, the roasting did not lead to high levels of PAHs, which were all well below the levels usually reported for vegetable oils.

These observations suggest that it is not useful to omit the roasting step for the sake of the preservation of antioxidants, and that the right roasting conditions do not lead to excessive formation of PAHs. In contrast, roasting is necessary to obtain the characteristic oil appearance and flavor. Within the tested conditions, the choice of roasting temperatures and time might depend therefore rather on sensory characteristics of the produced pumpkin seed oil.

\section{Abbreviations}

CA(E), caffeic acid (equivalents); FLD, fluorescence detector; GA (E), gallic acid (equivalents); HPLC, high performance liquid chromatography; MSD, mass spectrometric detector; PAHs, polyaromatic hydrocarbons; PSO, pumpkin seed oil; SPE, solid phase extraction; TPC, total phenolic compounds.

\section{Acknowledgments}

The authors would like to gratefully acknowledge Ghent University, São Paulo Research Foundation (2014/21252-0), and National Council for Scientific and Technological Development (406856/2013-3) for financial support.

\section{Conflicts of Interest}

The authors declare no conflict of interest.

\section{Keywords}

pumpkin seed oil, roasting, tocopherols, phenolic compounds, HPLC-MS

Received: February 28, 2017

Revised: July 19, 2017

Published online: October 13, 2017

[1] S. Poehlmann, P. Schieberle, J. Agric. Food Chem. 2013, 61, 2933.

[2] Y. Saucedo-Hernández, M. J. Lerma-García, J. M. Herrero-Martínez, G. Ramis-Ramos, E. Jorge-Rodríguez, E. F. Simó-Alfonso, J. Agric. Food Chem. 2011, 59, 4125.

[3] B. Siegmund, M. Murkovic, Food Chem. 2004, 84, 367.

[4] M. Murkovic, V. Piironen, A. M. Lampi, T. Kraushofer, G. Sontag, Food Chem. 2004, 84, 359.

[5] V. Vujasinovic, S. Djilas, E. Dimic, Z. Basic, O. Radocaj, Eur. J. Lipid Sci. Tech. 2012, 114, 568.

[6] M. D. Guillén, P. Sopelana, G. Palencia, J. Agric. Food Chem. 2004, 52, 2123.

[7] K. Dost, C. Ideli, Food Chem. 2012, 133, 193.

[8] T. Potočnik, I. J. Košir, Influence of roasting temperature of pumpkin seed on PAH and aroma formation. Eur. J. Lipid Sci. Tech. 2017, 119, 1500593. https://doi.org/10.1002/ejlt.201500593

[9] AOCS, Method Ce 8-89, Official methods and recommended practices of the American Oil Chemist's Society. AOCS, Champaign, IL, USA 1996.

[10] M. Andjelkovic, J. Van Camp, M. Pedra, K. Renders, C. Socaciu, R. Verhé, J. Agric. Food Chem. 2008, 56, 5181.

[11] M. Andjelkovic, J. Van Camp, A. Trawka, R. Verhé, Eur. J. Lipid Sci. Tech. 2010, 112, 208.

[12] B. Veyrand, A. Brosseaud, L. Sarcher, V. Varlet, F. Monteau, P. Marchand, F. Andre, B. Le Bizec, J. Chromatogr. A 2007, 1149, 333.

[13] C. Brasseur, F. Brose, A. Pirlot, C. Douny, G. Eppe, G. MaghuinRogister, M.-L. Scippo, Accredit. Qual. Assur. 2007, 12, 535.

[14] S. Danyi, F. Brose, C. Brasseur, Y.-J. Schneider, Y. Larondelle, L. Pussemier, J. Robbens, S. De Saeger, G. Maghuin-Rogister, M.L. Scippo, Anal. Chim. Acta. 2009, 633, 293.

[15] G. O. Fruhwirth, A. Hermetter, Eur. J. Lipid Sci. Tech. 2008, 110 637.

[16] E. Uitterhaegen, K. Sampaio, E. Delbeke, W. De Greyt, M. Cerny, P. Evon, O. Merah, T. Talou, C. Stevens, Molecules 2016, 21, 1202.

[17] D. G. Stevenson, F. J. Eller, L. Wang, J.-L. Jane, T. Wang, G. E. Inglett, J. Agr. Food Chem. 2007, 55, 4005.

[18] M. H. Ng, C. Yuen May, J. Chromatogr. Sci. 2012, 50, 283. 
[19] A. Siger, M. Nogala-Kalucka, E. Lampart-Szczapa, J. Food Lipids 2008 15, 137.

[20] Andjelkovic, M. Determination and biofunctional potential of phenolic compounds in olive oil and selected specialty oils. Thesis submitted in fulfilment of the requirements for the degree of Doctor
(PhD) in Applied Biological Sciences. Faculty of Bioscience Engineering, University of Ghent. 2009.

[21] J. Parry, Z. Hao, M. Luther, L. Su, K. Zhou, L. Yu, J. Am. Oil Chem. Soc. 2006, 83, 847.

[22] European Commission, Official J. Eur. Union 2006, 5. 